\title{
VERB PATTERNS IN TRIAL DISCOURSE: THE CASE OF I THINK
}

\author{
Magdalena Szczyrbak
}

\begin{abstract}
This study revisits the usage of $I$ think in courtroom interaction based on transcripts from a murder trial. The analysis focuses on the structural diversity of $I$ think and some of its variant forms, and it demonstrates pragmatic functions associated with the individual patterns. As the data reveal, I think performs the roles reported in earlier studies (discourse marker, hedge, booster, face-saving device, opinion marker, mindsay marker) as well as increases epistemic distance and decreases the degree of imposition in courtroom questioning. The findings obtained in the current research are also compared with Kaltenböck's (2013) results documenting various uses of I think and other comment clauses in diachronic spoken data. This comparison demonstrates that, on the one hand, well-established patterns involving I think are frequent in the courtroom data and, on the other, that the recent trends with variant forms of $I$ think - which have been identified in non-specialist settings - are scantily represented.
\end{abstract}

\section{Keywords}

comment clauses, epistemic stance, I think, jury trial, mental verbs, trial discourse

\section{Introduction}

Given their indeterminate nature, comment clauses with cognitive verbs (subsuming mental and perception verbs) are an interesting linguistic phenomenon whose frequency in spoken interaction is high. As revealed by recent corpus-based studies (e.g. Van Bogaert 2006, Brinton 2008, Kaltenböck 2013), their patterns of use have been continually changing, which is well illustrated by the most central of all comment clauses, i.e. I think, and its epistemic meaning giving way to new pragmatic functions. In fact, there is growing corpus evidence showing new patterns with I think and its variant forms (e.g. I'm thinking and I just think) across various settings; however, their deployment in specialised discourses seems to have attracted less attention. For that reason, building on the existing research into comment clauses, on the one hand, and epistemic phenomena, on the other, this study revisits the usage of $I$ think in courtroom interaction based on transcripts from a murder trial. The analysis focuses on the structural diversity of I think and some of its variant forms, and it demonstrates pragmatic functions associated with the individual patterns. The findings obtained in the current study are also compared with Kaltenböck's (2013) results documenting various uses of 
I think and other comment clauses in diachronic spoken data. This comparison demonstrates that, on the one hand, well-established patterns involving I think are frequent in the courtroom data and, on the other, that the recent trends with variant forms of I think - which have been identified in non-specialist settings are scantily represented.

\section{I think in earlier research}

The discourse role of I think, the most frequent and most prototypical of all parenthetical verbs, has been the focus of much scholarly attention. The phrase, in its different guises, has been described by various researchers highlighting, for instance, the degree of its pragmaticalization and its particle status (Aijmer 1997, Fetzer 2014), its comment clause use in conventional and variant forms (Kaltenböck 2013) as well as its stance, politeness and discourse marker roles in conversation (Kärkkäinen 2003, Mullan 2010).

First of all, it has been observed that "main clause-like" comment clauses (Quirk et al. 1985: 1112) like I think "typically provide some epistemic qualification of the proposition in a host clause, and can occur in initial, medial or final position" (Kaltenböck 2013: 286). Given the fact that it may take the that-complementizer, I think can be analysed as a matrix clause, even though its syntactic status is not clear. Thus, it may have secondary status also in initial position (ibid.). The ambivalent nature of parentheticals like $I$ think has been attributed to "a discrepancy between usage and structure" and the fact that although structurally such comments represent clauses, "functionally they are like disjunct adverbials conveying secondary information" (ibid.: 287).

Elsewhere, I think has been classified as a non-factive predicate (alongside believe or guess) which may be used parenthetically because it does not form the main part of the message, but rather expresses the speaker's state or attitude to the utterance (Aijmer 1997: 7). At the same time, when that is used, I think "is more likely to express an objective and informative statement about the speaker's beliefs" (ibid.: 8). Finally, it has been recognised that, as a pragmatic element, I think expresses epistemic modality and as such, it conveys various attitudes to knowledge.

As is the case with other mental verbs, the degree of certainty communicated by I think ranges from 'doubt (lack of certainty)' to 'lack of doubt (certainty)' and its meaning is determined by prosodic realisation, context and position (Mullan 2010). I think has thus been linked to speaker tentativeness and lack of commitment ("shield" function), attenuation of precision (approximating function), boosting (strengthening function) and, finally, to structuring discourse (structural function) (Kaltenböck 2010). I think in intonation-unit-initial position has also been described as a stance frame with which speakers "display a certain 
orientation towards propositions or parts thereof, or to a longer sequence of discourse" (Kärkkäinen 2003: 115). ${ }^{1}$ It has likewise been observed that $I$ think operates not only as a marker of doubt or opinion, but also as a recipient-oriented face-saving device (Mullan 2010: 122). Finally, depending on its position, the phrase has been found to perform a range of discourse organisational functions such as: marking discourse boundaries, initiating a new topic, summing up discourse, marking a new perspective in the upcoming turn, marking finality or signalling turn completion (ibid.).

The potential of $I$ think to structure information has been described in connection with its development from an epistemic marker to a general pragmatic marker with textual and interpersonal functions. As argued by Kaltenböck (2013), through semantic bleaching, I think has been losing its original meaning of non-commitment in favour of procedural meaning. In his view, the erosion of epistemic meaning is evidenced by the routinised use of initial- and medial-position I think which is linked to online planning and which frequently co-occurs with other discourse markers operating as fillers, starting points or stalling devices (ibid.: 301). At the same time, however, final-position $I$ think seems to have retained its function of an epistemic afterthought mitigating the preceding statement (ibid.: 295).

Among the newer patterns of use whose frequency is increasing, Kaltenböck (2013: 297) identifies phrasal scope $I$ think which is found i.a. in elliptical or incomplete sentences, where it is more of an approximator (often co-occurring with numerals) than an epistemic marker. It has also been hypothesized that due to the semantic erosion of I think, its variant forms attested by corpus data (e.g. I'm thinking, I just think, I'd think, I'm just thinking, I would think) ${ }^{2}$ may be taking over the epistemic meaning originally associated with this phrase, thus filling a functional "vacancy" (ibid.: 302). To support this claim, Kaltenböck (ibid.: 303) refers to comment clause uses of I'm thinking which, in his view, may well be replaced by I think without major change in meaning. ${ }^{3}$ He makes similar observations about I'm guessing, noting that in the Corpus of Historical American English (COHA) "there is a clear indication that I'm guessing is used increasingly as a modal marker that is close in meaning to I think" (ibid.: 305). Other likely candidates include I'd think and I just think $k^{4}$, in the case of which, however, there is insufficient corpus evidence to confirm their interchangeability with epistemic I think. Last but not least, Kaltenböck (ibid.: 299-300) draws attention to non-standard uses of $I$ think which is flexible enough to function as an independent response, often turn-initially, for instance as an alternative to I think so. Corpus evidence also shows that I think is employed as a quotative (mindsay) verb reporting the speaker's thoughts, where, conversely, it seems to 
have retained the original meaning of 'cogitation' (ibid.: 300). Such occurrences are however rare. Summing up, the different uses of I think discussed above point to the continuous bleaching of this phrase and "attest to its functional flexibility as a result of semantic erosion" (ibid.).

\section{Patterns with I think in the Tsarnaev trial}

\subsection{Aims, method and data}

The study reported here investigates to what extent there is evidence of the patterns with $I$ think discussed in Section 2 in courtroom talk. It specifically looks at how participants in an American jury trial deploy I think and its variant forms to interactionally co-construct their stances. Being a corpus-assisted discourse study, the investigation seeks, broadly, to discover how, in the courtroom setting, discourse participants behave, how they interact and what their discourse aims are (Partington et al. 2013: 12). More precisely, the study examines the distribution of the focal forms and, further, it identifies the functions that these forms perform in the epistemological positioning of the speakers' claims. The study follows the quantitative-then-qualitative sequence (Partington 2017: 344): first, it looks at quantitative information obtained with the help of a concordance tool (Wordsmith Tools v. 5) and next, it explains how I think functions in particular contexts, for which close reading of recurrent patterns was needed.

The study makes use of thirty-three transcripts (totalling slightly over 1 million words) from the trial of the Boston Marathon bomber Dzhokhar Tsarnaev. Tsarnaev was charged with "using and conspiring to use a weapon of mass destruction resulting in death" and with "malicious destruction of properties resulting in death" as well as with the murder of a police officer. He was found guilty on all counts and sentenced to death by lethal injection. ${ }^{5}$ The transcripts cover "the guilt phase" and "the penalty phase" of the trial (which took place from March till May 2015). Interestingly, the defendant remained silent throughout the whole trial and he made only one statement on the last day of the proceedings.

The transcripts are useful for studying discourse-pragmatic phenomena related to the communication of knowledge and no-knowledge, including, in particular, the way speakers with conflicting interactional goals negotiate epistemic priority. Relevant to the focus of the study is therefore the participant structure of the trial involving not only the opposing parties (defence team vs prosecution) and their witnesses but also a participatory audience (judge) and a non-participatory one (jurors). Since the Tsarnaev trial followed the adversarial procedure typical of the Anglo-American judicial system, the opposing parties strove to have their 
narratives accepted by the judge and the jury. This found reflection in the patterns of use of subjective markers such as I think, guiding the audience's perception of the claims advanced by the speakers.

With this background, I now proceed to the central part of this paper, that is the analysis of patterns with $I$ think in the trial transcripts.

\subsection{Findings}

\subsubsection{Preliminary observations}

Overall, the data showed that the word form think was relatively frequent and, second, that most of its uses were in the first-person singular (Tables 1 and 2). Unsurprisingly, the present non-progressive form I think was far more frequent than the progressive thinking and the past form thought. In addition, a comparison of the figures obtained for other first-person epistemic verbs confirmed that I think was by far the most preferred mental predicate, with I believe and I guess taking the second and third positions (Table 2). It also became apparent that other mental verbs were in general less readily recruited.

\begin{tabular}{|l|r|}
\hline & \multicolumn{1}{|c|}{ No. of tokens } \\
\hline think & 1,853 \\
\hline thought & 326 \\
\hline thinking & 110 \\
\hline thinks & 18 \\
\hline will think & 2 \\
\hline
\end{tabular}

Table 1: Frequency distribution of think in the trial corpus

\begin{tabular}{|l|r|}
\hline & \multicolumn{1}{|c|}{ No. of tokens } \\
\hline I think & 1,298 \\
\hline I believe & 569 \\
\hline I guess & 192 \\
\hline I understand & 94 \\
\hline I assume & 26 \\
\hline I suppose & 15 \\
\hline I gather & 9 \\
\hline I find & 7 \\
\hline I suspect & 6 \\
\hline I imagine & 5 \\
\hline
\end{tabular}

Table 2: Frequency distribution of selected first-person mental verbs in the trial corpus

In addition, following an analysis of 3-word clusters with think, it transpired 
that: 1) the negated form I don't think was the most common cluster, 2) I think with the zero complementizer was much more frequent than its counterpart with that and, finally, that 3) the phrase and I think, described as a salient pattern in political discourse (Fetzer 2014: 81), was among the most frequent clusters in the courtroom data as well (Table 3).

\begin{tabular}{|l|r|}
\hline & \multicolumn{1}{|c|}{ No. of tokens } \\
\hline I don't think & 189 \\
\hline I think it & 125 \\
\hline and I think & 120 \\
\hline I think it's & 102 \\
\hline I think you & 88 \\
\hline court I think & 84 \\
\hline I think I & 84 \\
\hline I think the & 83 \\
\hline I think we & 78 \\
\hline I think that & 63 \\
\hline
\end{tabular}

Table 3: The most common 3-word clusters with think in the trial corpus

\subsubsection{Structural diversity}

As already noted, I think exhibits structural and formal flexibility "which causes it to straddle grammar and discourse" (Aijmer 1997: 7). As such, the phrase can occur in different positions in the utterance; it is flexible in terms of tense, aspect and modality and, further, it can be negated and questioned (ibid.). These observations are corroborated by the material analysed in the current study. Table 4 shows the positional distribution of $I$ think in the data, whereas Table 5 displays the frequency of variant forms of I think. As can be seen, the proportions between clause-initial, -medial and -final occurrences of I think in the data reflect trends reported elsewhere, with initial $I$ think greatly outnumbering the remaining categories (cf. Aijmer 1997, Kaltenböck 2013).

At the same time, it can be observed that first-person modalised forms with think are infrequent and that progressive constructions are used sparingly. Among the variant forms, only two appear to be more readily recruited than others: I don't think (being at the same the most frequent 3-word cluster) and the past form I thought. Examples illustrating the structural and formal diversity of I think are provided below. In the examples, "D" refers to the defence counsel, "P" to the prosecutors, " $\mathrm{C}$ " to the court (judge) and "W" denotes witnesses.

\begin{tabular}{|l|l|}
\hline & No. of tokens \\
\hline
\end{tabular} 


\begin{tabular}{|l|r|}
\hline I think $\varnothing$ & 1,065 \\
\hline$\ldots$ I think ... & 112 \\
\hline$\ldots$, I think. & 37 \\
\hline I think that & 26 \\
\hline
\end{tabular}

Table 4: Positional distribution of $I$ think in the trial corpus

\begin{tabular}{|l|r|}
\hline & \multicolumn{1}{|c|}{ No. of tokens } \\
\hline I don't think & 189 \\
\hline I thought & 174 \\
\hline I didn't think & 18 \\
\hline I was thinking & 17 \\
\hline I think so & 14 \\
\hline I would think & 6 \\
\hline I'm thinking & 5 \\
\hline I do think & 4 \\
\hline I did not think & 3 \\
\hline I just think & 1 \\
\hline I was just thinking & 1 \\
\hline
\end{tabular}

Table 5: Variant forms of $I$ think in the trial corpus

As noted previously, I think was found in clause-initial position with (Example 1) or without (Example 2) the that-complementizer.

(1) P: Actually, your Honor, I think that we are probably going to conduct most, if not all, of this in English, but we have the interpreter just in case Mr. Meng needs the interpreter.

(2) C: Okay. I think you need a witness, so maybe you can get one.

Rather unsurprisingly, I think operated not only as a complement-taking predicate, as shown in Examples 1 and 2 above but also as a 'main clause-like' comment clause occurring medially or finally, as illustrated by Examples 3 and 4 .

(3) D: And there was testimony from, I think, both the FBI and from you suggesting that Tamerlan Tsarnaev was the principal user of that one?

W: Correct.

(4) P: About how long were you in the hospital as a result of your injuries?

W: I think it's around 20 to 30 days, I think. It's hard to track the time. 
Less expected, and yet pragmatically interesting, were instances of phrasal scope uses of $I$ think like the ones shown in Examples 5, 6 and 7. Prince et al. (1982, as cited in Kaltenböck 2013: 297) link such uses to the attenuation of precision and scalar approximation, and the data at hand show a similar trend.

D: How long have you been a Cambridge public schoolteacher? W: I think 16 years.

(6) D: In preparing what the jury has now seen, the multiple-page, I think 14-page document, did you take any notes in preparation of that?

$\mathrm{W}$ : No.It's all just done on the computer utilizing the records and the tower list and the mapping and so forth.

(7) D: The child was going to return to Boston, but the bombing occurred and the father, I think rather rightfully, held onto the child until things could -

C: Well --

In sum, regarding the structural diversity of I think, the trial data exhibit patterns similar to the ones noted in other interactional contexts.

\subsubsection{Functional diversity}

Not only the structural but also the functional diversity of $I$ think was attested by the current dataset, which agrees with earlier findings revealing a wide range of pragmatic functions associated with this phrase. The uses which seem to be the most prominent in the courtroom context include the deployment of I think as a discourse-organising device and a hedge; the use of and I think as a booster; the use of I think to preface confirmation-seeking questions with verba dicendi, the use of I think and I don't think as face-saving devices; and, finally, the deployment of progressive forms to signal deliberation ((and) I'm thinking) as well as to report the speaker's thoughts and feelings (I was thinking). To illustrate each of the above functions, relevant examples are discussed below.

\section{I think as discourse marker}

First of all, it was found that $I$ think acted as a discourse marker linked both to online planning and interpersonal involvement. This can be seen in Example 8, where I think co-occurs with other discourse-organising devices (you know; first of all; I'd like to say) and epistemic qualifiers (it seems to me), all of which precede the counsel's opinion itself. Similarly, the discourse-organising and the interpersonal function of I think are to be observed in Example 10, where I think is prefaced by well, I mean. This agrees with what Kaltenböck (2013:299) observes 
about $I$ think in initial and medial position and its increased co-occurrence with other discourse markers (e.g. I mean, well, actually, you know), on the one hand, and the decreased co-occurrence with short and long pauses signalling disfluency, on the other. Based on diachronic corpus evidence, Kaltenböck (ibid.) concludes that $I$ think is a filling device which "alleviates production difficulties" and replaces disfluency features such as pauses.

(8) C: This appears to just express her reaction to learning about his involvement. I think I've already excluded that from other people.

D: I think, you know, your Honor, first of all, I'd like to say that it seems to me that the reaction that we've been trying to get has to do with lay witness opinion about character, which is relevant in this portion of the proceedings.

(9) D: Perhaps -- it is one o'clock right now. Perhaps we could think about it a little bit and think of a way out of it.

P: Well, I mean, I think if the defense wants to make an issue that the receipt for a holster was found in Tamerlan's wallet, I think it's only fair for the government to be able to ask questions whether a holster was found on Tamerlan or anywhere else. If the holster is completely out of the case, we don't have any objection to that, but otherwise, it's speculative.

\section{I think as hedge}

As expected, I think was also found to mark the speaker's non-commitment and lack of certainty. The mitigating effect of parenthetical I think is illustrated by Examples 10 and 11. In the first one, it co-occurs with the low certainty markers about and maybe, which results in the attenuation of the speaker's precision. In the other one, I think is inserted before a specific date is mentioned and it follows a short pause signalling the speaker's indeterminacy. It should be added that the hedging function of I think in contexts similar to the ones illustrated here was not uncommon in the data, especially in narratives related to times, measurements and locations. The patterns noted in the trial data provide evidence in support of the claim that I think itself may not be an "adequate" carrier of uncertainty, which results in its co-occurrence with other epistemic markers (Kärkkäinen 2003: 129).

P: So you turned onto Commonwealth Avenue, and where did you go?

W: After Commonwealth -- we continued on Commonwealth Avenue for about,

I think, maybe two miles, until we made a right turn near Brighton.

P: Are you familiar with the one-family-one-child policy in China?

W: Yes. Yes.

P: Can you just briefly explain what that is? 
W: That thing, it started 19--- I think 1970. I was the last one, last generation. My parents, you know, able to have two. I have a sister. But since I think 1978 or '77 it started, you know, to control the population. So it's a one-child policy.

Irrespective of the above, other contexts with 'softening' I think were also noted. These included co-occurrences of I think with other mental verbs (e.g. I think + I believe) or with perception verbs indicating the source of information (e.g. I think + I heard). For instance, I think in Example 12 prefaces the speaker's commitment signalled with the semantically more determinate I believe acting as a booster. I think in Example 13, in turn, appears to be a 'shield' which weakens the effect of heard. In this case, using the bare direct evidential I heard would have been more committal than its hedged counterpart with I think.

It is also worth noting here that Examples 12 and 13 illustrate what may be referred to as 'protective packaging'. Such additional linguistic material introduces indirectness and may thus be likened to "a verbal icon of an envelope around the speaker's actual message" which protects the hearer "from the speaker's ideas in the same way that he is protected by physical distance from other emanations of a personality" (Haiman 1983: 80, as cited in Biel 2007: 180). In agreement with this, it may be argued that I think performs the role of a 'protective envelope' or 'epistemic packaging' which adds more indirectness and decreases the speaker's commitment to the message.

P: Tell us what happened.

W: After I think -- I believe it was two days but I'm not exactly sure, but I believe it was two days and then I was told that they were going to have to amputate my leg. (...)

D: Now, you heard about this secondhand?

W: Yeah.

D: From another -- from an administrator or from Jahar?

W: I think I heard about it from an administrator. I talked to him about it, but I think I heard about it from the administrator.

\section{and I think as booster}

Apart from the hedging of what would otherwise have been categorical assertions, I think performed the role of a booster. This was especially prominent in the cluster and I think which, as noted earlier, turned out to be common in the courtroom data at hand. The strengthening function of this pattern is shown in Examples 14 and 15, where and I think makes explicit the speaker's chain of argument and indicates "that the argument to follow is a firm backing of the 
previous one" (Fetzer 2014: 81). Thus, as may be argued, it marks both firm commitment and argumentative continuity. To see this more clearly, one may consider the use of and I think with the that-complementizer linked to deliberative uses of think (Example 14) or the deployment of and so I think (Example 15) marking standpoint continuity not only with and but also with resultative so.

D: Do you know if he did participate in that the following year?

$\mathrm{W}$ : I don't think the program got off the ground, and I think that Jahar went to a different school in seventh grade.

P: Your Honor, the Court asked the defense for a very detailed proffer of what Sister Helen said. We went into the back, and the government objected to certain parts of it. Primarily what the government objected to were things about her experience, which I didn't touch on. Other than that, with respect to the sentence that was in the proffer that he spoke to her, that the government moved vigorously to keep out and the defense moved vigorously to keep in, it stayed in. And so I think it was appropriate to refer to that.

\section{I think + verba dicendi in confirmation-seeking questions}

Turning now to the questioning strategies, co-occurrences of $I$ think with verbs of speaking appeared to characterize the questioners' discourse. On closer inspection, three distinctive patterns were identified: I think + verbum dicendi in declarative (prosodic) questions (Example 16); I think + verbum dicendi in declarative questions appended turn-finally (Example 17) and I think + verbum dicendi followed by a question tag (Example 18). All of them are confirmation-seeking questions and they suggest the preferred response drawing on earlier testimony. In particular, the I think you cluster was followed by reporting verbs such as ('ve) told us, said, talked, indicated, described or testified. When preceded by I think, they marked greater epistemic distance.

(16) D: I think you've told us that that was a fair and accurate representation of the Mercedes going towards you?

W: Yup.

D: So it's fair to say from what you've seen there, there actually is another car parked there next to where you are tackling Tamerlan?

$\mathrm{W}$ : I would say yes.

(17) P: Eventually, Ruslan came to the United States to live here, correct?

W: Yes.

P: And when he came here, he visited you in Washington, I think you said?

$\mathrm{W}$ : Well, since I was living in his house, yes, he visited. 
(18) P: At one point__ I think you described on direct examination that the Tsarnaev family came and lived with him in Kazakhstan, is that right?

$\mathrm{W}$ : The children came and lived with him.

P: And that includes Tamerlan, Bella, and Ailina?

W: Tamerlan was there, and I believe Ailina and Bella were, too.

\section{I (don't) think as face-saving device}

Apart from its distancing role in questions, $I$ think was also found to act as a face-saving device. In fact, both I think and I don't think were linked to politeness. Being the stronger alternative of the two, the negated form seemed to stress the emotional character of what was being said as well as weakened bluntness (cf. Tottie 1991) and signalled reduced epistemicity (cf. Pichler 2009: 565). This is clear in Example 19, where the expert witness tries to save face and explain his lack of confidence by pointing it out to the defence counsel that computer-generated data in general cannot be trusted. I think, on the other hand, mitigates face threats in an unemotional fashion, as shown in the following two excerpts, where the speaker communicates an objection to the evidence presented in court (Example 20) and admits to having misled the witness (Example 21). The use of I think in Example 20 may be interpreted as the speaker's intention to reduce the possible unwelcome effect on the hearer, whereas its deployment in Example 21 appears to be an indirect apology.

(19) D: So how do you know the difference? How can we interpret any one of these items what it means? Are you able to do that sitting here today?

$\mathrm{W}$ : Not sitting here today, no. We would need further analysis on the file. The file does exist on the computer, and the file entry does exist on the directory listing.

D: But you're not confident about the dates in these spreadsheets?

W: I don't think any forensic person would ever be a hundred percent confident in dates and times generated by the operating systems.

(20) D: So I'd like to show another photograph, Exhibit 3419.

P: Just for the witness, please. I think I have an objection to this one.

D: Oh, I'm sorry. Not 3419. I got my numbers wrong. 3507-053A. I'm not going to be offering 3419, Ms. Pellegrini. Do you have an objection to this one?

P: No.

(21) P: I think I misled you before with one of my questions. This particular receipt, was this one found in a Honda CR-V registered to Tamerlan Tsarnaev?

W: Yes.

P: All right. My mistake. I apologize. 


\section{(and) I'm thinking as deliberative marker}

Since the following three excerpts (Examples 22, 23, and 24) include the progressive form of think, a brief comment on the use of this construction is in order. As earlier research suggests (Szczyrbak in press), the use of progressives with think in courtroom talk is linked to three types of meaning: 1) cogitation; 2) holding an opinion and 3) "interpretative" use (cf. Huddleston \& Pullum 2002). Similar patterns have also been found in political discourse, where I am thinking is used to clarify a preceding segment of discourse or to talk about a situation prior to the time of speaking in order to make the narrative more vivid (Martinez Vazquez 2018: 115). In such contexts, preposition dropping is common, which is evidenced by the courtroom data as well, even though, admittedly, only five occurrences of the present progressive I'm thinking were identified. Two of them are presented in the excerpts below. In Example 22, I'm thinking is used to clarify the preceding statement and as such, it might be replaced by I mean. In Example 23 , in turn, and I'm thinking focuses on the judge's consideration of the time of the hearing (cf. meaning 1 above).

P: How far away from you did that one explode?

$\mathrm{W}$ : I can't be sure. I know it was -- the vehicle was in front of me. I'm thinking it was probably right about here when it went off, and the device was in front of that.

C: Okay. So I'm not sure that there's one particular time we should set for motions but I want - there's at least one motion, I guess, that we need to perhaps resolve before the government's case, and that is the defendant's motion with respect to Dr. King. And I'm thinking we could have a hearing on that on Monday.

\section{(and) I was thinking as mindsay marker}

While the present progressive of think was indeed infrequent in the data, its past counterpart was attested by more occurrences. I was thinking was used as a mindsay structure (cf. Bednarek's (2006) distinction between "hearsay" and "mindsay") just like its non-progressive counterpart I thought; however, only the progressive construction conveyed the intensity of the speaker's feelings. To see the difference, consider Examples 24 and 25. In the first of them, the witness repeats $I$ was thinking in his narrative to reflect his emotional state at the time of the tragic event, which - coupled with the frequent use of rapport-building you know and quotative like - increases the expressiveness of the testimony. The non-progressive form I thought did not carry the same emotional load, as may be seen in Example 25. 
(24) W: (...) And I think someone put a jacket over me at that point. And, you know, I laid there for a while and I was thinking, you know, "This is how it's going to end." You know, "This is it." (...)

And then I was thinking, it was, like, "I had a great life. I had a great life." I saw the world, and, you know, I played sports growing up, I had great friends and I experienced a lot in my 26, 27 years on this planet. And I kind of made peace with myself at that point. And, you know, then something clicked. You know, I did hear the second explosion and, you know, I was thinking, you know, "This is messed up. "I was, like, "We're under attack." That's what I was thinking on the ground. (...)

(25) P: Can you estimate about how long you were on the sidewalk before you got taken away from the scene?

W: They asked me in the hospital and I said -- you know, I thought it was like 20 minutes. It seemed like a lifetime to me laying there. And, you know, I guess it was only a couple -- like probably about five minutes I was there.

\section{Conclusion}

In line with findings from other studies, the main conclusion to be drawn from the current investigation is that $I$ think performs a range of pragmatic functions which are not necessarily related to the communication of (un)certainty. Thus, the analysis adds more evidence to the literature available on pragmatic functions of I think as the trial data corroborate the structural flexibility, the functions and the collocations of I think reported elsewhere (Aijmer 1997, Kaltenböck 2010, 2013). Also, in agreement with earlier studies, the analysis shows that, in the data at hand, I think is favoured in initial position without a complementizer and that medial and final $I$ think is much less frequent. The full form I think that, conversely, is rare. As predicted, co-occurrence with discourse-organising devices (e.g. well, I mean) and modal markers (e.g. maybe, probably) is likewise attested. Interestingly, phrasal scope uses of I think are visible in the data, too.

On the other hand, there is little evidence of the variant forms of I think believed to be taking over its epistemic meaning, as suggested by the data discussed in Kaltenböck (2013: 302). The few examples of I'm thinking that have been found indicate, however, intensity and expressiveness. So does I was thinking which serves chiefly to report the speaker's thoughts (mindsay) alongside its unemotional non-progressive counterpart $I$ thought. What is more, I'm just thinking and I just think, shown to be on the rise in spoken data (ibid.: 305), each occurred only once, which does not support their interchangeability with epistemic $I$ think (at least in the 2015 trial data analysed here).

Regardless of the above, two new patterns have been identified: one in the questioners' discourse and one in the witnesses' turns, both of which may be 
referred to as a 'protective envelope' or 'epistemic packaging' of the proposition. As it turned out, in the data, the examiners preface their confirmation-seeking questions containing reporting verbs with I think to decrease the degree of imposition, be it in declarative questions (I think you said...?), in declarative questions appended turn-finally (..., I think you said?) or in declaratives followed by a question tag (I think you described...., is that right?). The witnesses, in turn, tend to qualify their statements containing perception verbs with I think to avoid full commitment to the proposition (I think I heard). At the same time, I think co-occurs with more determinate mental verbs, with the latter acting as boosters (I think ... I believe).

In light of the above it may be concluded that patterns with I think underlie the epistemic positioning of the trial participants. Some of them appear to be typical of the courtroom register: with the questioners using I think to decrease the degree of imposition during questioning (thus demonstrating a lawyer's way of thinking and talking) and the witnesses using I think to increase epistemic distance (thus distancing themselves from categorical assertions). Such usage seems to reflect the Anglo mode of thought, i.e. "[t]the cultural imperative of acknowledging the limitations of one's knowledge" and the consequent need to distinguish between what one knows (i.e. knowledge) and what one thinks (i.e. judgment) (Wierzbicka 2006: 35).

Finally, I think appears to be not only a stance marker, but also a phrase which frames upcoming stanced turns or opinion sequences and which performs facework at "points of trouble in interaction" (Kärkkäinen 2007: 183). All things considered, given the decreased subjectivity and the general referentiality of $I$ think noted in earlier research (Traugott 1995, Scheibman 2001), it remains to be seen how new patterns with this phrase evolve and how they begin to take over the meanings which once resided in well-established patterns. However, for new trends to be identified in specialist and non-specialist settings, more data representing various discourses will have to be investigated.

\section{Notes}

1 Elsewhere, it has been suggested that both I think and I guess (in American English) "display and project an upcoming stanced action and organize the stancetaking activity between participants, rather than themselves indexing an interactionally strong and salient stance" (Kärkkäinen 2007: 185).

2 Drawing on Van Bogaert (2009, 2010), Kaltenböck (2013: 301) suggests that variant forms of I think be viewed as part of an expanding constructional network or a more schematic "mesoconstruction" (Traugott 2007), with I think being its prototypical member. In this approach, I think is seen as "a template and pacemaker for the entire taxonomy, leading other variant forms (as well as other complement-taking mental predicates) to higher levels of entrenchment" (Kaltenböck 2013: 301). 
3 As Kaltenböck (2013: 303) notes, diachronic data from the Corpus of Historical American English (COHA) show a correlation between a considerable decrease in the use of I think (from the 1980s onwards) and an increase in the use of I'm thinking.

4 In his discussion about the discourse role of I just think, Emet (2017) highlights two meanings of the phrase: attenuation of the force of speaker commitment, and the "new" meaning which he refers to as "an all-things-considered judgment". Put differently, as Emet (2017) suggests, apart from its scalar usage, I just think can convey decisiveness as well as "indicate that one will continue to hold one's view in the face of disagreement".

5 At the time of writing this article, Tsarnaev is awaiting execution in the United States Penitentiary Administrative Maximum Facility in Fremont County, Colorado.

\section{References}

Aijmer, K. (1997) 'I think - an English modal particle.' In: Swan, T. and Westvik, O. J. (eds) Modality in Germanic Languages: Historical and Comparative Perspectives. Berlin: Mouton de Gruyter. 1-47.

Bednarek, M. (2006) 'Epistemological positioning and evidentiality in English news discourse - a text-driven approach.' Text \& Talk 26(6), 635-660.

Biel, Ł. (2007) 'Communicative distance in interaction: Verbal and nonverbal expression in English.' In: Kiełtyka, R., Osuchowska, D. and Rokosz-Piejko, E. (eds) Language, Literature, Culture and Beyond. Festschrift for Grzegorz A. Kleparski on his $50^{\text {th }}$ Birthday. Rzeszów: Wydawnictwo Uniwersytetu Rzeszowskiego. 175-183.

Brinton, L. (2008) The Comment Clause in English. Syntactic Origins and Pragmatic Development. Cambridge: Cambridge University Press.

Emet, S. (2017) 'I just think...: The meaning and discourse role of just.' Online document. 1 May 2019<http://research.clps.brown.edu/linglangfiles/2017-03-01\%20-\%20 'I\%20just $\% 20$ think' $\% 20$-\%20The $\% 20$ meaning\%20and $\% 20$ discourse $\% 20$ role $\% 20$ of $\% 20$ 'just $\% 20$ (Steve\%20Emet,\%20Brown).pdf

Fetzer, A. (2014) 'I think, I mean and I believe in political discourse. Collocates, functions and distribution.' Functions of Language 21(1), 67-94.

Haiman, J. (1983) 'Iconic and economic motivation.' Language 59, 781-819.

Huddleston, R. and Pullum, G. K. (2002) The Cambridge Grammar of the English Language. Cambridge: Cambridge University Press.

Kaltenböck, G. (2010) 'Pragmatic functions of parenthetical I think.' In: Kaltenböck, G., Mihatsch, W. and Schneider, S. (eds) New Approaches to Hedging. Amsterdam: Elsevier. 243-272.

Kaltenböck, G. (2013) 'The development of comment clauses.' In: Aarts, B., Close, J., Leech, G. and Wallis, S. (eds) The Verb Phrase in English. Investigating Recent Language Change with Corpora. Cambridge: Cambridge University Press. 286-317.

Kärkkäinen, E. (2003) Epistemic Stance in English Conversation: A Description of its Interactional Functions, with a Focus on I think. (Pragmatics \& Beyond New Series, 115). Amsterdam and Philadelphia: John Benjamins.

Kärkkäinen, E. (2007) 'The role of I guess in conversational stancetaking.' In: Englebretson, E. (ed.) Stancetaking in Discourse. Amsterdam and Philadelphia: John Benjamins. 183-219.

Martinez Vazquez, M. (2018) 'A corpus-based study of I am thinking in political speeches.' Revista de Lenguas para Fines Especificos 24(2), 107-123.

Mullan, K. (2010) Expressing Opinions in French and Australian English Discourse. Amsterdam and Philadelphia: John Benjamins.

Partington, A. (2017) 'Varieties of non-obvious meaning in CL and CADS: From hindsight post-dictability to sweet serendipity.' Corpora 12(3), 339-367. 
Partington, A., Duguid, A. and Taylor, C. (2013) Patterns and Meanings in Discourse: Theory and Practice in Corpus-assisted Discourse Studies (CADS). Amsterdam and Philadelphia: John Benjamins.

Pichler, H. (2009) 'The functional and social reality of discourse variants in a northern English dialect: I DON'T KNOW and I DON'T THINK compared.' Intercultural Pragmatics 6(4), 561-596.

Prince, E. F., Frader, J. and Bosk, C. (1982) 'On hedging in physician-physician discourse.' In: Di Pietro, R. J. (ed.) Linguistics in the Professions: Proceedings of the Second Annual Delaware Symposium on Language Studies. Norwood, NJ: Ablex. 83-97.

Quirk, R., Greenbaum, S., Leech, G. and Svartvik, J. (1985) A Comprehensive Grammar of the English Language. London: Longman.

Scheibman. J. (2001) 'Local patterns of subjectivity in person and verb type in American English conversation.' In: Bybee, J. and Hopper, P. (eds) Frequency and the Emergence of Linguistic Structure. Amsterdam and Philadelphia: John Benjamins. 61-89.

Scott, M. (2012) WordSmith Tools (version 6), Stroud: Lexical Analysis Software.

Szczyrbak, M. (in press) 'I'm thinking and you're saying. Speaker stance and the progressive of mental verbs in courtroom interaction.'

Tottie, G. (1991) Negation in English Speech and Writing. San Diego: Academic Press.

Traugott, E. C. (1995) 'Subjectification in grammaticalisation.' In: Stein, D. and Wright, S. (eds) Subjectivity and Subjectivisation. Cambridge: Cambridge University Press. 31-54.

Traugott, E. C. (2007) 'The concepts of constructional mismatch and type-shifting from the perspective of grammaticalization.' Cognitive Linguistics 18, 523-557.

Van Bogaert, J. (2006) 'I guess, I suppose and I believe as pragmatic markers: Grammaticalization and functions.' Belgian Journal of English Language and Literatures (new series) 4, 129-149.

Van Bogaert, J. (2009) The Grammar of Complement-taking Mental Predicate Constructions in Present-day Spoken British English. PhD dissertation. University of Ghent.

Van Bogaert, J. (2010) 'A constructional taxonomy of I think and related expressions: accounting for the variability of complement-taking mental predicates.' English Language and Linguistics 14(3), 399-427.

Wierzbicka, A. (2006) English: Meaning and Culture. Oxford: Oxford University Press.

\section{Sources}

Tsarnaev trial transcripts. Available at: http://thebostonmarathonbombings.weebly.com/ trial-transcripts.html (accessed on 1 February 2018).

Magdalena Szczyrbak is Assistant Professor at the Institute of English Studies, Jagiellonian University, Kraków, Poland. Her research interests are mainly in the areas of discourse analysis and corpus-assisted discourse studies applied to legal discourse and, in particular, to the study of stance and evaluation.

Address: Magdalena Szczyrbak, Institute of English Studies, Faculty of Philology, Jagiellonian University, al. Mickiewicza 9a, 31-120 Kraków, Poland. [e-mail: magdalena.szczyrbak@uj.edu.pl] 